\title{
Motives for the choice of not undergoing breast reconstruction
}

\author{
Zdzisława Szadowska-Szlachetka', Marianna Charzyńska-Gula', Katarzyna Muzyczka', \\ Beata Dobrowolska², Andrzej Stanisławek ${ }^{1}$ \\ ${ }^{1}$ Chair of Oncology and Environmental Care, Faculty of Health Sciences, Medical University of Lublin, Poland \\ ${ }^{2}$ Chair of Development in Nursing, Faculty of Health Sciences, Medical University of Lublin, Lublin, Poland
}

Szadowska-Szlachetka Z, Charzyńska-Gula M, Muzyczka K, Dobrowolska B, Stanisławek A. Motives for the choice of not undergoing breast reconstruction. J Pre-Clin Clin Res. 2016; 10(1): 39-44. doi: 10.5604/18982395.1208187

\begin{abstract}
Introduction and objective. Currently, most women with less advanced breast cancer are offered operations with breast conserving treatment; however, if it is necessary to completely remove the breast, the patients may benefit from free breast reconstruction. The aim of the study was to determine the motives for breast reconstruction after mastectomy or decisive reasons for rejecting this treatment.

Material and methods. The study included 241 women hospitalized in Polish oncological hospitals who were divided into two groups: $55.19 \%(n=133)$ were women after mastectomy; 44.81\% $(n=108)$ after breast reconstruction. Quantitative approach with the use of survey method was utilised.

Results. Women who wished to undergo breast reconstruction were generallyy younger, better educated and more often professionally active. For women who wished to undergo breast reconstruction, the most important aspect was the willingness to improve their body image, their mental well-being, the inconvenience connected with wearing the prosthesis, better sexual relations with husband/partner, and the possibility of exposing the neckline without discomfort. The strongest correlation was found between women's young age and their functioning in a relationship. Women after mastectomy, who decided not to undergo a breast reconstruction, were afraid of another operation, suffering, and they believed that there were more important issues.

Conclusions. The study revealed a relationship between the lack of knowledge, in which hospital breast reconstruction procedure can be performed and the lack of motivation for undergoing the procedure. Women who have had knowledge of the possibility of a free breast reconstruction were younger, better educated and more often lived in the city.
\end{abstract}

\section{Key words}

breast cancer, breast reconstruction motives

\section{INTRODUCTION}

Breast reconstruction gives women suffering from breast cancer certain psychological benefits, reflected in a higher quality of life, better perception of one's body and a lowered level of fear and depression. It makes it possible to regain complete emotional and mental health in the crisis caused by breast cancer and is the last step towards regaining a positive image of one's body. Both the number of breast reconstructions, the immediate and those delayed, as well as procedures connected with carrying them out (source of financing the procedure) are different in particular countries. For instance, in 1994 and 1995 in the USA, the number of reconstructions after mastectomy amounted to approx. $8.3 \%$, and in the UK and Ireland - 18\%. In many industrialised countries, in turn, in some specialist hospitals breast reconstruction after mastectomy is carried out in $50 \%$ of women. In France, each woman after mastectomy can undergo breast reconstruction for free. In 2011-2013, in hospitals in Lublin, Poland, 1,780 mastectomies in total were performed and as little as 97 breast reconstructions, accounting for only $5.5 \%$ of the total number of the procedures.

Address for correspondence: Beata Dobrowolska, Chair of Development in Nursing, Faculty of Health Sciences, Medical University, Staszica 4-6, 20-081 Lublin, Poland E-mail: bb.dobrowolska@gmail.com

Received: 14 February 2016; accepted: 20 June 2016
The objective of the present study is to define the motives for breast reconstruction or the reasons determining the decision against undergoing this procedure in a sampled group of women.

Reconstructive treatment should be considered as an integral part of the treatment of breast cancer [1]. The first breast reconstructive surgery was performed by Vincenz Czerny 1893 in Vienna [2] by transplanting lipoma taken from another area - the surgery was not successful. The proper origins of reconstructive surgery are associated with the period after the Second World War [3]. When it comes to the history of reconstruction in Poland, the first such surgery was performed in 1985 in the present Surgery Department of the Breast Cancer and Reconstructive Surgery Clinic at M. Sklodowska-Curie Oncological Centre in Warsaw. Reconstruction with Bommert's epigastric flap and endoprosthesis was used (this flap is no longer used). At the beginning of 1986, the first breast reconstruction was performed there with an insular myocutaneous flap containing the latissimus dorsi muscle (broadest muscle of the back), completed with endoprosthesis. A year later, own modification of this method was introduced allowing for the use of the flap itself - without the use of prosthesis. Further techniques were introduced in subsequent years. In 1987, the use of equipment for the expansion of tissue - the so-called expandable implants - was initiated. After obtaining the proper expansion, an endoprosthesis was placed at that site. In collaboration with a team of anesthesiologists, anesthesia 
with prolonged epidural infusion of lidocaine in the thoracic section was used in reconstruction surgeries, which allowed the performance of some surgeries in ambulatory conditions. The turning point was performance of reconstruction surgeries with the use of a transverse insular myocutaneous flap containing rectus abdominis muscle - i.e. only with autologous - own tissues.

In order to improve the blood supply of these flaps, own modification of this method was developed. In 1996, the first such operations with the use of microsurgical anastomosis of small arteries and veins under the microscope were performed.

Currently, the newest immediate reconstructions are performed - with sparing the patient's own breast skin. Elements of reconstructive surgery were also introduced to the sparing treatment. Year after year, the technique of reconstruction surgery has been improved, and latest achievements of surgeons from the world's leading clinics were transferred to the Warsaw Clinic, and own modifications that entered the world's literature were introduced. Own original rehabilitation programme was developed [4].

Many centres in Poland - public and private health care institutions - perform surgeries within breast reconstruction. In recent years, the leading centres more and more often successfully perform mastectomy with areola incision, removing the entire gland with areola and nipple and sparing own breast skin (skin-sparing mastectomy). A necessary element of such a procedure is immediate reconstruction with the use of own tissues or implants - expander prostheses [5]. A further development of this method is an areolasparing mastectomy - breast and nipple are removed - skin and areola are left [6]. Such a procedure should take place in reference centres in which it is possible to conduct very detailed post-surgery tests in preinvasive cancer, or during prophylactic mastectomy [7].

Crove et al. from the Cleveland Clinic (Cleveland, Ohio, USA) perform 'nipple-and areola-sparing mastectomy' and control the nipple-areola tissues during the surgery. In the initial series of 54 surgeries, cancer cells were found and classic mastectomy performed in six cases [8]. Women undergoing immediate reconstruction tend to accept new breasts as an integral part of their body [9] and show decreased psychosocial effects, they also have much less concern due to the fact that the removed breast reminded them about the surgery [10. It is less probable that such women who do not accept the reconstructed breast feel more comfortable when dressing up than women who did not undergo mastectomy [11]. The psychosocial benefits of breast reconstruction are widely recognized [12].

There is no doubt that the reconstruction has many benefits for women who choose it: it improves life quality, improves own body image, reduces fear and depression, and many women are pleased with the results. However, many women may be dissatisfied and unhappy after reconstruction [13].

Reconstruction is not the breast in its true meaning, it feels and looks different than the healthy breast, it also makes breast-feeding impossible. The surgeon should objectively explain the method of reconstruction to the patient, the course of the surgery, its planned result, emphasize that the reconstructed breast will vary to some extent from the other breast. The surgeon should also describe the negative side of treatment - the need of, i.a. another stay in the hospital, length of treatment, pain after surgery and new scars. The patient should also be informed about possible complications. Only the patient having this information may feel ready to make a decision about breast reconstruction [14].

Studies show that women fully informed about the various possibilities of breast reconstruction feel better [15]. Oncologists and surgeons can sometimes underestimate the impact of stress and confusion of their patients on inadequate communication and making the wrong decisions about treatment [13]. It is important to explain the available options to the patient, without persuading her to any of them when discussing the breast reconstruction [16]. It should not be assumed that the reconstruction will always bring psychiatric advantages to patients; therefore, the information provided should always be objective [17].

In Poland, the therapeutic team dealing with a woman who decides to undergo reconstruction consists of an oncologist, plastic surgeon, psychologist and physiotherapist [18].

Apart from the patient's education, it is necessary to provide information to family and friends who support the patient. These people may not always be present during the meetings with the surgeon, but may affect the patient's decision and therefore need objective information. Full use of modern educational tools may facilitate the task of educating patients and their relatives about breast reconstruction [19]. It is more likely that a well-informed patient will have more realistic expectations and will be more pleased with the final result. A plastic surgeon must provide basic technical information of the operation (for example, methods, possible complications, additional procedures, etc.). Heller \& Miller [19] state that they have created an interactive computer programme as an educational tool for women preparing for breast reconstruction entitled 'Breast Reconstruction: What You Need To Know' which includes three-dimensional animated images, photographs of results and video explanations of plastic surgeons and other medical specialists. It also includes stories of women who explain why they chose a specific method of breast reconstruction and how it affected their lives.

\section{MATERIALS AND METHOD}

The analysed group $(n=241)$ of people consisted of two subgroups: women after mastectomy - 133 persons from the Lublin Province of eastern Poland, and women after breast reconstruction, and 108 persons from the Lublin Province and from Warsaw. The average age of the surveyed subgroup amounted to $51.05 \pm 8.55$ years. $75.94 \%$ of the respondents were from cities, and $24.06 \%$ lived in villages. Married women were the most numerous group among the respondents $(69.92 \%), 11.27 \%$ were widows, $9.77 \%$ were divorced and $9.02 \%$ were single. The average age of the second surveyed subgroup was $49.30 \pm 8.84$ years. $76.85 \%$ of respondents were from cities, while $23.15 \%$ from villages. The most numerous among this group were also married women $(55.56 \%)$, widows accounted for $4.63 \%$, the divorced for $15.74 \%$, and $24.07 \%$ were single.

The research method employed was diagnostic survey with the use of two versions of a questionnaire. The questionnaire contained questions on personal details, the applied treatment (chemotherapy, radiotherapy, hormonal treatment). It also investigated the motives behind the choice of reconstruction of the two groups of women, the sources of information on 
the possibilities of performing breast reconstruction, and in the group of women after mastectomy, the reasons for not undergoing reconstruction.

Before starting the research, the authors received approval of the Ethical Commission at Medical University of Lublin (Ref. No.: KE-0254/45/2007).

The obtained results were subject to a statistical analysis. The values of the analysed measurable parameters were presented by means of the average value and standard deviation, and for the non-measurable parameters, with the use of cardinality and proportion. For the measurable attributes, the normality of the breakdown of the analysed parameters was assessed with the use of the ShapiroWilk test. In order to compare two independent groups, the Mann-Whitney test was applied. For more than two groups, the Kruskal-Wallis test was used. For the purpose of recognising the differences between the analysed groups, the homogeneity or independence $\chi 2$ test was applied. For analysis of the correlation between two quantitative attributes, the significance test of the Spearman's correlation coefficient was employed. In order to assess the probability of making the decision about breast reconstruction, logistic regression was used, enabling such an analysis of data in which an endogenous probability variable is within the $[0-1]$ range. The considered medical problem deals with the endogenous variable of a dichotomic type, 1 meaning making the decision for breast reconstruction, 0 - deciding against it. An important aspect here is the answer to a question: which of the exogenous variables significantly influences the fact of making the decision for breast reconstruction? The regression coefficient $(Z)$ obtained as a result of analysis after a logarithmic conversion, assumes the value within the [0-1] range, which defines the probability of the occurrence of motivation for breast reconstruction in relation to particular clinical cases.

\section{RESULTS}

In the group of women after mastectomy, $39.10 \%$ were willing to undergo breast reconstruction $(n=52)$, while $60.90 \%(n=81)$ refused. The average age of the respondents who would like to have breast reconstruction performed amounted to 46.50 years, while the average age of the women who did not wish to undergo the procedure was 53.97 years. No significant correlation was observed between the willingness to undergo breast reconstruction and marital status $(\mathrm{p}=0.16)$. However, it was discovered that the analysed element is closely connected with education level $(\mathrm{p}=0.03)$. The respondents who wanted to have breast reconstruction carried out most often had higher education (42.31\%) or secondary education (36.54\%) (Tab. 1). The willingness to undergo breast reconstruction was most often expressed by working women (44.23\%) as well as those being on a temporary pension (34.62\%), while the retired respondents did not wish to have the procedure performed $(p<0.001)$. Analysis of various aspects of life of the surveyed women influencing the undergone reconstruction, which would be significant for the decision of women after mastectomy concerning undergoing it in the future, enabled enumeration of the following motives for their decisions: young age of a woman, improving one's body image, improving one's mental well-being, social functioning, functioning in a relationship (with a husband, with a sex
Table 1. The motivation for breast reconstruction versus education level

\begin{tabular}{lcccc}
\hline $\begin{array}{l}\text { Motivation for breast } \\
\text { reconstruction }\end{array}$ & $\begin{array}{c}\text { Primary/ } \\
\text { Vocational }\end{array}$ & Secondary & Higher & Total \\
\hline & $\mathrm{n}$ & $\mathrm{n}$ & $\mathrm{n}$ & $\mathrm{n}$ \\
$\%$ & 11 & 19 & 22 & 52 \\
\hline Positive & $21.15 \%$ & $36.54 \%$ & $42.31 \%$ & $100.00 \%$ \\
\hline Negative & 16 & 46 & 18 & 81 \\
\cline { 2 - 5 } & $20.00 \%$ & $57.50 \%$ & $22.50 \%$ & $100.00 \%$ \\
\hline
\end{tabular}

Statistical analysis: $\mathrm{Chi}^{2}=6.91 ; \mathrm{p}=0.03^{*}$

partner), the possibility of exposing the neckline without discomfort, and inconvenience connected with wearing a prosthesis.

For the women $(n=52)$ who wanted to undergo the reconstruction, the most important aspect was the wish to improve their body image (71.47\%), improvement of mental well-being (68.59\%), inconvenience of wearing the prosthesis (67.31\%), as well as the possibility of exposing the neckline without discomfort (66.35\%), while age, social functioning and functioning in a relationship were of slightly lesser importance.

Significant negative correlations were found between the time elapsed since mastectomy and the importance of aspects of the decision to undergo breast reconstruction. Together with the passage of time since the mastectomy, the significance of particular aspects became lower. The strongest correlation was found regarding young age and functioning in a relationship. For the women after breast reconstruction, the most important reason for making the decision was the inconvenience connected with wearing the prosthesis (81.94\%), improvement of their mental well-being (79.63\%), improvement of their body image $(74.85 \%)$ and the possibility of showing the neckline without discomfort (67.13\%), while age, social functioning and functioning in a relationship had a lower influence. Significant negative correlations were found between time elapsed since mastectomy and the importance of the above-mentioned aspects of the decision. Together with the passage of time since mastectomy, the significance of particular aspects became less important. Comparing the group after mastectomy and the one after breast reconstruction, significant differences were found only in the aspect of inconvenience related to wearing a prosthesis $(\mathrm{p}=0.02)$. The prosthesis was much more 'burdensome' for women after breast reconstruction. The remaining aspects were equally important for women who had already undergone the reconstruction and the surveyed after mastectomy who wished to undergo the procedure of breast reconstruction. (Fig. 1). The survey shows that the respondents after breast reconstruction $(n=108)$ most often made the decision on their own (67.59\%), while $12.04 \%$ of the surveyed admitted that they made the decision together with their husband or partner, and $31.48 \%$ made the decision together with their surgeon. Most frequently the surveyed women had a breast implant (expander prosthesis) (87.04\%), while only $6.48 \%$ had the reconstruction performed with the use of a spinal muscle, and the same percentage of women - with an abdominal muscle.

As many as $85.19 \%$ of the surveyed women admitted that the procedure of breast reconstruction fulfilled their expectations, while women who were not satisfied with 


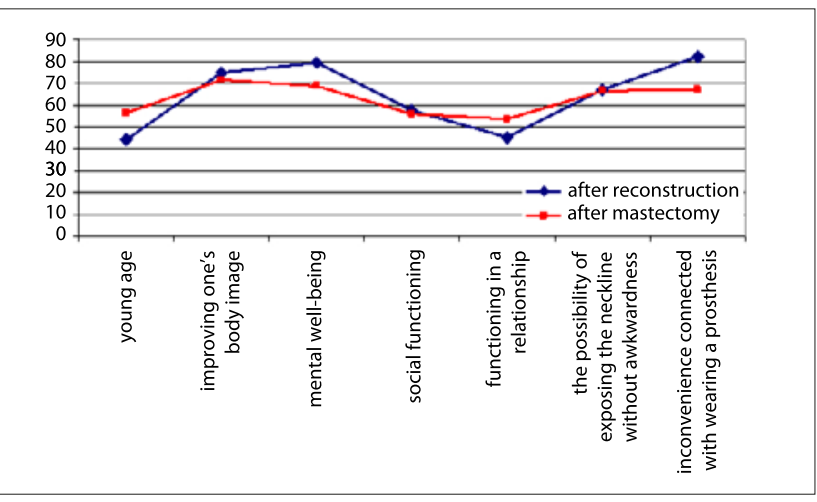

Figure 1. Comparison of the importance of aspects of the decision to undergo breast reconstruction between the group of women after mastectomy and the group after breast reconstruction

the result accounted for only $14.81 \%$. Most frequently, the surveyed were in a better disposition, their mental condition improved, they felt like returning to normal life. Some of the surveyed who claimed that the procedure did not meet their expectations gave the following reasons: the difference between the other breast, different shape of the new breast, too many scars, hardness of the breast. As many as $95.37 \%$ of the women admitted that they would make the decision to undergo breast reconstruction again, while only $4.63 \%$ would not make the same decision again.

The respondents most frequently received information on the possibility of undergoing breast reconstruction from a doctor on the ward where the mastectomy was carried out $(50.93 \%)$ or in an oncology clinic $(35.19 \%)$, or from women after mastectomy (13.89\%), while cases when the information came from nurses were rare.

In the group of women after mastectomy $39.10 \%$ wanted to undergo breast reconstruction, while $60.90 \%$ claimed that they did not. In the group of women after mastectomy who admitted that they did not want to undergo breast reconstruction $(n=81)$ the most common reasons were 'other more important matters' (37.04\%), 'fear of further suffering' $(34.57 \%)$ and 'fear of another surgery' (32.10\%), as well as age $(29.63 \%)$. Only $17.28 \%$ mentioned having got used to the breast prosthesis, and $8.64 \%$ of the surveyed admitted that they had not received any information on the reconstruction procedure, while only $1.23 \%$ women claimed that the hospital in which it was possible to undergo the procedure was too far away from their home.

A significant correlation was shown between the will to undergo breast reconstruction and the age at which the mastectomy was performed $(\mathrm{p}<0.001)$, as well as the current age of the surveyed women $(\mathrm{p}<0.001)$. Both the older age and the period of time which passed since the mastectomy decreased the willingness to undergo breast reconstruction. The average age of the respondents who wanted to undergo breast reconstruction amounted to 46.50 years, while that of women who did not express such a wish was at the level of 53.97 years. The survey demonstrated that $82.71 \%$ of respondents (women after mastectomy) knew that they could undergo free breast reconstruction, while only $17.29 \%$ were not aware of that. In the survey no significant correspondence was found between the willingness to undergo breast reconstruction and the knowledge about the possibility of undergoing the procedure for free $(\mathrm{p}>0.05)$. The survey demonstrated that as many as $82.71 \%$ women after mastectomy knew about the possibility of free breast reconstruction, while only $17.29 \%$ of respondents claimed that they were unaware of it. As a result of the statistical analysis carried out it, was stated that the surveyed who had knowledge about free breast reconstruction were younger in comparison to those who did not have such knowledge $(50.15 \pm 8.33$ vs. $55.39 \pm 8.41)$, $(\mathrm{Z}=-2.94 ; \mathrm{p}<0.01)$. It was found that the surveyed women after mastectomy who lived in cities knew about the possibility of free breast reconstruction slightly more often (85.15\%) in comparison to women from the village (75.00\%); however, no statistically significant differences were determined between the two groups, $\left(\mathrm{Chi}^{2}=1.75 ; \mathrm{p}>0.05\right)$.

Statistical analysis demonstrated that the respondents after mastectomy who were employed knew about the possibility of free breast reconstruction considerably more often $(94.87 \%)$ than women who did not work $(77.66 \%),\left(\mathrm{Chi}^{2}=5.71 ; \mathrm{p}<0.05\right)$.

The survey showed that $68.42 \%$ women after mastectomy knew that breast reconstruction can be carried out with the use of the patient's own tissue, through a partial transplant of an abdominal muscle or a spinal muscle, while $31.58 \%$ women admitted that they did not have knowledge on this subject.

The performed survey also revealed that the surveyed women after mastectomy who admitted that they knew the ways in which breast reconstruction can be carried out, more often expressed a wish to undergo it (59.62\%), compared to the respondents who did not have the knowledge in this area $(25.93 \%)(\mathrm{p}<0.001)$.

Most of the surveyed did not know where in the Lublin Province it is possible to undergo free breast reconstruction $(60.90 \%)$, while $39.10 \%$ of the respondents admitted that they have knowledge on this issue.

\section{DISCUSSION}

The survey carried out for the purposes of the presented study concerning women after mastectomy shows that $39.1 \%$ of the women would like to undergo breast reconstruction. American studies, in turn, comprising 1,844 women from Detroit and Los Angeles, demonstrate that only 35\% decided to undergo breast reconstruction, despite knowledge of the possibility of having this procedure carried out. The lack of knowledge on breast reconstruction and more frequent focus on barriers connected with this procedure occurs more often in the case of Afro-Americans and worse-educated women, which points to the necessity for applying a better educational strategy towards this group [20]. In Finland, $28 \%$ of 111 patients who had mastectomy wanted to undergo breast reconstruction. The average age of respondents after mastectomy who wished to undergo breast reconstruction amounted to 46.50 years, while that of women who did not wish to have this procedure performed -53.97 years. Other authors report that the average age of women undergoing breast reconstruction is between 40-42 [21, 22].

The presented study indicates that the most important reason for making the decision to undergo breast reconstruction for women after mastectomy $(n=52)$ was the willingness to improve their body image (71.47\%), and their mental well-being (68.59\%). Among the reasons there were also the inconvenience connected with wearing the prosthesis $(67.31 \%)$ as well as the possibility of exposing the neckline without discomfort (66.35\%). In turn, age, functioning in the society and in a relationship were of secondary importance. 
A retrospective survey demonstrates that the most important factors influencing the decision of women who were already after breast reconstruction, was the inconvenience of wearing the prosthesis $(81.94 \%)$, the improvement of their mental well-being (79.63\%), willingness to improve their body image (74.85\%), as well as the possibility of showing the neckline without discomfort (67.13\%). The age of the surveyed, social functioning and functioning in a relationship had a lower impact on the decision. In another study, for most of the women the reason for making the decision to undergo breast reconstruction is the willingness to maintain normal physical appearance [23]. Meretoja gives the following main reasons for the decision to undergo breast reconstruction for women in Finland: problems with one's body image, inconvenience connected with wearing the prosthesis or inability to accept it, low self-esteem, willingness to forget about the cancer, and doctor's recommendations [24]. In a study carried out by Harcourt, the reasons for making the decision about breast reconstruction for 103 surveyed women were: the importance of their own body image, self-esteem, understanding of the essence of cancer and of the surgical procedure of breast reconstruction, the sense of gaining self-control, demographic and social indicators, the opinion of the environment, including the medical personnel, and the hospital in which the surgery was performed (including procedures and waiting time) [25]. Morrow, after carrying out a retrospective survey on 70,000 women after mastectomy in the USA, pointed out that the choice of breast reconstruction depends on many factors: age, the state of the tumour, the income of the patient, ethnic origin, and the type of hospital in which the surgery was performed [26]. In a Swedish study, age, feeling of attractiveness and sexual interest were associated with the choice of whether or not to undergo breast reconstruction [27]. Callaghan, in turn, after carrying out a survey on approx. 400 surgeons from the UK and Ireland, came to the conclusion that undergoing breast reconstruction depends on the location of the hospital and characteristics of the surgeon [28]. Many patients chose the procedure of breast reconstruction in order to avoid wearing an external prosthesis [29]; which was confirmed also by the results of the presented survey $(81.9 \%$ of the respondents after breast reconstruction mentioned this factor as the reason for undergoing the surgery).

The results of the current study demonstrate that the respondents after breast reconstruction $(n=108)$ most frequently made the decision to undergo this procedure on their own ( $n=73 ; 67.59 \%)$, while $12.04 \%(n=13)$ of the surveyed admitted that their husband or partner participated in the decision. 34 women $(31.48 \%)$ made the decision together with their surgeon. The survey also shows that $82.71 \%(n=110)$ of the respondents after mastectomy knew that they can undergo breast reconstruction free of charge. Most frequently, the surveyed women after mastectomy learned about breast reconstruction from a doctor on the ward where the mastectomy was carried out (37.59\%), or from a doctor in the oncology centre (27.07\%), slightly less often from women after the mastectomy procedure (24.81\%) or from the press $(24.06 \%)$, while $21.80 \%$ women obtained the information from the radio or television, $7.52 \%$ from a nurse on the oncological surgery ward, 5.26\% from a nurse in the oncology centre, while $8.27 \%$ from other sources, (in the Amazons Club, from the Internet, from literature, from the family). As a result of the survey carried out within this study, it was found that as many as $84.21 \%(n=112)$ of the surveyed women after mastectomy knew that breast reconstruction can be carried out through placing a breast implant. The survey also indicates that $68.42 \%(\mathrm{n}=91)$ of women after mastectomy knew that breast reconstruction can be performed through a partial transplant of an abdominal muscle or a spinal muscle. Most of the surveyed women did not know where in the Lublin Province free breast reconstruction could be carried out $(n=81 ; 60.90 \%)$. The lack of knowledge on this matter was correlated with negative motivation in relation to this procedure.

In a study carried out in England it was stated that 26.8\% women claimed that they did not receive a sufficient amount of information for making the decision concerning breast reconstruction, of which $36.1 \%$ did not undergo breast reconstruction after mastectomy, $13.8 \%$ underwent the procedure immediately, and $33.3 \%$ had a delayed breast reconstruction [17]. In the group of the surveyed women after mastectomy who admitted that they did not want to undergo breast reconstruction $(n=81)$, the most common reason for this decision was 'other more important matters' (37.04\%), 'fear of further suffering' (34.57\%) and of another surgery (32.10\%), as well as age (29.63\%). Only $17.28 \%$ mentioned getting used to the prosthesis, $8.64 \%$ of the surveyed admitted that they did not have any information about breast reconstruction, and the same percentage gave other reasons, while only $1.23 \%$ claimed that the distance to the nearest hospital in which the procedure can be performed is too far. In relation to women who were currently after mastectomy, it was also stated that the more time passed from the mastectomy and the older the age of a woman, the more rarely these women decided to undergo breast reconstruction. According to Mac [13], breast reconstruction can be carried out with good results after months and years following mastectomy but when women do not choose immediate breast reconstruction, they can get used to living with the prosthesis and resign from breast reconstruction. In a population of women in Finland the main reasons for the decision against reconstruction are the following: being satisfied with the present situation, the surgery is too problematic, fear of surgery, and the fact that the surgery would make the women recall the cancer [24]. Similar reasons were found in French research in which refusal of further surgery, acceptance of body asymmetry, risk of complications and advanced age were the most common [30].

\section{CONCLUSIONS}

The relationship between lack of knowledge in which hospital breast reconstruction procedure can be performed and the lack of motivation for undergoing it was discovered in the study. Women who have had knowledge of the possibility of a free breast reconstruction were younger, better educated and more often lived in the city.

\section{REFERENCES}

1.Lee CN, Belkora J, Chang Y, Moy B, Partridge A, Sepucha K. Are patients making high-quality decisions about breast reconstruction after mastectomy? Plast Reconstr Surg. Jan 2011; 127(1): 18-26.

2. Goldwyn RM. Vincenz Czerny and the beginnings of breast reconstruction. Plast Reconstr. Surg. 1978; 61: 673-680. 
3. Gilles HD, Millard DR. Principles and art of plastic surgery. Boston 1957, Little Brown, pp. 297- 300.

4.Lewandowska H. Sposoby na nową pierś. Sprawy Nauki. Biuletyn Ministra Nauki i Szkolnictwa Wyższego. 2005;4:109-111 (in Polish).

5. Fersis N, Hoenig A, Rlakis K. Skin - sparing mastectomy and immediate breast reconstruction incidence of recurrence in patients with invasive breast cancer. Breast 2004; 139: 488- 493.

6. Simmons RM, Hollenbeck ST, Latrenta GS. Two - year follow - up of areola sparing mastectomy with immediate reconstruction. Am J Surg. 2004; 188: 403-406.

7. Towpik E. Rak piersi. Przegląd Piśmiennictwa Chirurgicznego 2004; 8: 82-88. (in Polish)

8. Crove JP, Kim JA, Yetman R, Banbury J, Patrick RJ, Baynes D. Nipple - sparing mastectomy: technique and results of 54 procedures. Arch Surg. 2004; 114:1551-1552.

9. Magarey C J. Aspects of the psychological management of breast cancer. The Med J Australia. 1988; 148: 239-242.

10. Wellisch DK, Schain WS, Noone R B, Little J W. III Psychosocial correlates of immediate versus delayed reconstruction of the breast. Plast Reconstr Surg. 1985; 76:713-718.

11. Stevens L A, McGrath M H, Druss R G, Kister S J, Gump F E, Forde K A. The psychological impact of immediate breast reconstruction for women with early breast cancer. Plast Reconstr Surg. 1984; 73: 619-628.

12. Brandberg Y, Malm M, Bloquist L. A prospective and randomized study, "SEVEA" comparing effects of three methods for delayed breast reconstruction on quality of life, patient - defined problems area of life and cosmetic result. Plast Reconstr Surg. 2000; 105:66-74.

13. Mac D. Choices following mastectomy. Practice Nurse 2006; 22:9:15831592.

14. Towpik E, Mazur S, Witwicki T, Tchórzewska H. et. al. Operacje odtwórcze piersi z użyciem ekspandera/protezy Beckera. Nowotwory 1999; 4, (49): 425-427. (in Polish).

15. Hack TF. The communications goals and needs of cancer patients: a review. Psycho-Oncology 2005;14: 831-845.

16. Nano TM, Gill PG, Kolias J, et al. Qualitative assessment of breast reconstruction in a specialist breast unit. ANZ. J Surg. 2005; 75:445-453.

17. Harcourt DM, Rumsey N, Ambler NR, et al. The psychological effect of mastectomy with and without breast reconstruction. Plastic Reconstr Surg. 2002; 111(3): 1060-1068.
18. Fedorczuk A. Odzyskana kobiecość. Nowotwór. Newsweek Polska. 2006; (9): 89-91 (in Polish)

19. Heller L, Miller MJ. Patient Education and Decision Making in Breast Reconstruction. Semin Plast Surg. May 2004; 18(2): 139-147.

20. Morrow M, Mujahid M, Lantz PM, et al. Correlates of breast reconstruction. Results of population based study. Cancer 2005; 1(104): 2340-2346.

21. Al- Ghazal SK, Fallowfield L, Blamey RW. The psychological impact of immediate rather than delayed breast reconstruction. Eur J Surg Oncol. 2000; 26: 17-19.

22. Gul GP, Tan SM, Falakou EC, et al. Immediate breast reconstruction using biodimensional anatomical permanent expander implants: a prospective analysis of outcome and patient satisfaction. Plast Reconstr Surg. 2003; 111: 125-138.

23. Fentiman S, Hamed H. Breast reconstruction. J Clin Pract. 2006; 60(4): 471-474.

24. Meretoja E, Souminen E. Demand for plastic surgical operations after primary breast cancer. Scandinavian J Surg. 2005; 94: 211-215.

25. Harcourt D, Rumsey N. Breast reconstruction: the psychological implications and reasoning behind decision made by women undergoing mastectomy following diagnosis of breast cancer. J Adv Nursing. 2001; 35(4): 477-487.

26. Morrow M, Scott SK, Menck HR, et al. Factors influencing the use of breast reconstruction postmastectomy: A National Cancer Database study. J Am Coll Surg. 2001; 92:1-8.

27. Fallbjörk U, Karlsson S, Salander P, Rasmussen BH. Differences between women who have and have not undergone breast reconstruction after mastectomy due to breast cancer. Acta Oncol. 2010; 49(2): 174-179. doi: $10.3109 / 02841860903490069$

28. Callaghan CJ, Couto E, Kerin MJ, Rainsbury RM, George WD. Purushotham AD. Breast reconstruction in United Kingdom and Ireland. Br J Surg. 2002; 89: 335-340.

29. Panieri E, Lazarus D, Dent DM, Hudson DA, et al. A study of the patient factors affecting reconstruction after mastectomy for breast carcinoma. Am Surg. 2003; 69: 95-97.

30. Héquet D, Zarca K, Dolbeaut S, Coutuaraud B, et al. Reasons of not having breast reconstruction: a historical cohort of 1937 breast cancer patients undergoing mastectomy. Springer Plus. 2013; 2: 325. doi:10.1186/2193-1801-2-325. 